\title{
VARIATION IN POLLINATOR POTENTIAL TO CARRY A BLUEBERRY FUNGAL PATHOGEN AND ASSESSMENT OF TRANSFER EFFICIENCY IN TWO MANAGED BEE SPECIES
}

\author{
Matthew D. H. Boyer and Lynn S. Adler* \\ Biology Department, University of Massachusetts Amherst, 221 Morrill Science Center South, 611 North Pleasant Street, Amherst, MA 01003
}

\begin{abstract}
Plant diseases are ubiquitous in agricultural systems and are major sources of economic loss. Vaccinium corymbosum, or highbush blueberry, is an economically important crop affected by an insect-vectored, fungal pathogen, Monilinia vaccinii-corymbosi, or mummy berry disease. Highbush blueberry yield is maximized through outcrossed pollination; however, the pathogen is vectored by pollinators. We used field collections and molecular techniques to identify floral visitors to highbush blueberry and quantify levels of pathogen spores carried by each visiting species. We also conducted a cage trial using single flower visits to determine differences in vectoring efficiency between two managed pollinators, Apis mellifera and Bombus impatiens. We found that bees, flies, and wasps were all common visitors, and that all bee species and several fly and wasp species carried the pathogen. Of the bee species, A. mellifera most often tested positive for the pathogen, while Dolichovespula maculata (Bald-faced Hornet) tested positive most among wasps and Mallota posticata among flies. Considering only individuals that tested positive, mummyberry levels per individual were highest in D. maculata and Andrena bees, and relatively low in flies. In cage trials, we found no differences between $A$. mellifera and B. impatiens in pathogen load or transfer efficiency, suggesting that these managed species are equally capable of vectoring mummyberry during a single visit to a blighted stem and then a flower. This research demonstrates the variety of floral visitors that carry mummyberry and that two common commercial pollinator species have similar potential to vector mummyberry to blueberry flowers during a single visit.
\end{abstract}

Keywords: Apis mellifera, blueberry, Bombus impatiens, floral pathogen, Monilinia vaccinii-corymbosi, Vaccinium corymbosum

\section{INTRODUCTION}

Over one third of the world's agricultural crops rely on insect-mediated pollination services to reproduce (Klein et al. 2007). A diverse assemblage of pollinators can increase yield as a result of flower visitation (Garibaldi et al. 2013). To increase the efficiency of pollination services, growers in North America often supplement the natural pollinator community with commercially available pollinators, Apis mellifera (European honeybee) or Bombus impatiens (common eastern bumblebee). Whether present naturally or supplemented by growers, bee pollination is vital to the economic prosperity and stability of agricultural systems (Delaplane \& Mayer 2000).

Despite the benefits provided by insect pollinators to many food crops, pollinators and other insect floral visitors may also transmit plant pathogens that reduce both fitness and yield (Dobson \& Crawley I994). At least 26 plant pathogens are vectored by pollinators that infect plant floral reproductive tissue (Roy 1994; McArt et al. 2014). For example, Microbotryum violaceum, or anther smut, is a common fungal pathogen vectored by insect pollinators that infect the plants in the family Caryophyllaceae (Jennersten 1988; Shykoff \&

Received I3 December 2018, accepted I2 April 2019

*Corresponding author: 1sadler@ent.umass.edu
Bucheli 1995). Additionally, Erwinia amylovora, or fire blight, is a bacterial pathogen carried by $A$. mellifera and other pollinators that infects apples, pears, and other crops in the Rosaceae, with domestic losses and control costs exceeding \$I00 million annually (Norelli et al. 2003). Describing variation in how floral visitors contribute to vectoring pathogens as well as pollinating crops may help to understand tradeoffs between balancing effective pollination services with disease management.

Highbush blueberry is an agriculturally important crop in the United States, with over 588 million pounds of berries produced from the 37,554 hectares dedicated to cultivated blueberry production (Ross et al. 2017). Monilinia vacciniicorymbosi (MVC), or mummy berry disease, is an insectvectored fungal pathogen that is the most damaging pathogen of highbush blueberry (Vaccinium corymbosum), with some infections reducing yield up to $80 \%$ and causing severe economic losses (Stretch et al. 200I). MVC employs a twostage infection process (Batra 1983). Primary infection by mummy-berry ascospores creates 'pseudoflowers' in new blueberry shoots, inducing the production of a sugar-rich solution, while causing blighted shoots to reflect UV light (Batra \& Batra 1985) and exude volatile organic compounds that mimic floral scent (McArt et al. 2016). In addition to distribution via wind and rain, pollinators and other insects visit the pseudoflowers and vector conidia, asexual fungal spores, to flowers (Ngugi et al. 2002). These spores mimic pollen grains by germinating on the stigma, and hyphal growth 
extends down the stylar canal from the conidium to the ovary, causing secondary infection (Ngugi \& Scherm 2004). Infected flowers develop inedible berries composed of hard, hyphal masses that drop, overwinter, and produce ascospores that begin a new cycle of infection (Batra 1983).

Vaccinium corymbosum is visited by a variety of insect pollinators, including bee species in the Andrenidae, Halictidae, Megachilidae, and Apidae families (Scott et al. 2016) that have the potential to vector MVC. Although mummy berry can be inhibited with repeated fungicide application, the cost of such applications and consumer demand for 'no spray' orchards, coupled with mounting environmental concerns over the use of fungicides (Wightwick et al. 20I0) make understanding which pollinators are most likely to vector the pathogen both relevant and economically desirable. Early work in this system established that floral infection is primarily vectored by insects that first visit blighted leaf tissue (Batra 1983), but until recently little was known about the specific insect taxa involved in transmission. Recent observational work combined with nested PCR analysis determined the presence of fungal spores on insect bodies and identified five Hymenopteran and nine Dipteran families as MVC carriers and potential vectors (McArt et al. 2016). Using camera traps to record visits to both flowers and blights, McArt et al. (2016) determined that although bees and flies often visited both blighted leaf tissue and flowers, bees were more likely to visit flowers than flies, and flies were more likely to visit blights than bees. Despite these behavioural differences, bees were more likely to be carriers of fungal spores than flies (McArt et al. 2016). The authors suggest that the discrepancy could be explained by differences in morphology between bees and flies, with the latter lacking branched hairs that are effective at collecting pollen and potentially conidia, or behavioural differences in contact and interaction with floral reproductive structures.

Behaviour and morphology can vary widely among insects, and insect pollinators differ in their pollination efficiency, both in the amount of pollen that can be picked up and in what is transferred from their bodies onto flowers (Primack \& Silander 1975; Herrera 1987; Olsen 1997). Since mummy berry conidia mimic pollen grains (Ngugi \& Scherm 2004), pollinators may also differ in their effectiveness as vectors for the pathogen. This variation can be caused by differences among pollinator taxa in cuticular structure, body fit to flower structure, or behaviour, such as pollen grooming or collecting nectar vs. pollen (Delaplane \& Mayer 2000; Adler \& Irwin 2006). Although previous work assessed the presence of fungal conidia on different insect pollinator taxa, we do not know the amount of conidia carried by these taxa, or how this relates to pollinator ability to transfer conidia to new host material. Depending on an insect's body shape, hairs, and way of interacting with flowers, presence or even quantity of conidia carried may not reflect the amount transferred to floral tissues. Therefore, we do not know whether insect pollinators differ in rates of transfer of mummy berry conidia.

The goals of this study were to assess (I) how much MVC is carried on insect taxa visiting $V$. corymbosum flowers and (2) the transfer efficiency of two commercially available pollinator species. We collected blueberry-visiting insects from a no-spray orchard infected with mummy berry. We then identified insect taxa to genus or species using cytochrome $\mathrm{c}$ oxidase I (COI) sequencing, and using a targeted sequencing approach combined with a competition assay, we estimated the amount of MVC carried on the sampled insects. Finally, we performed a cage trial to assess comparative transfer efficiency of mummyberry conidia by Apis mellifera and Bombus impatiens.

\section{MATERIALS AND METHODS}

\section{Insect field collection}

Insect visitors of highbush blueberry flowers were collected at Quonquont Orchard in Whately, Massachusetts, USA $\left(42.444^{\circ} \mathrm{N}-72.639^{\circ} \mathrm{W}\right)$ on May 22, May23 and June 4, 2014, periods of peak bloom. Collection took place on weekdays from 1000 to 1600 hours in weather conditions ranging from full sun to light rain. We did not net specimens to avoid rubbing off conidia due to contact with the net. Instead, we captured insects visiting flowers in snap-cap vials (one insect sample per vial) upon emergence from corollas. Specimen vials were immediately placed in dry ice for transport back to the lab. Two hundred and thirty-two samples were maintained in a $-20^{\circ} \mathrm{C}$ freezer until processing for molecular analysis; final sample sizes for each species are presented in Tab. I.

\section{Sequencing analysis}

Field-collected insects were sent to Floodlight Genomics LLC (Knoxville, TN) in snap-cap vials set in dry ice for processing to determine insect genus and species based on cytochrome c oxidase I (COI) sequencing and to measure the amount of MVC using a targeted-sequencing approach. Insects were weighed to determine wet mass prior to DNA extraction.

\section{DNA extraction}

Insects were assigned provisional identifications to order or family based on visual inspections (not removed from plastic containers). Provisional identifications are not reported and only served to confirm that molecular identification was reasonable for easily classified insects (e.g., Bombus). Unwashed insects were placed whole into $2 \mathrm{ml}$ or 5 $\mathrm{ml}$ tubes containing three to five $3 \mathrm{~mm}$ glass balls and freezedried for 24 hours. A mixer mill (Retsch GmbH, Germany) was used to disrupt and powder the freeze-dried material prior to genomic DNA extraction.

Genomic DNA was extracted using the MagJET Genomic DNA Extraction Kit (Thermo Fisher Scientific) according to the manufacturer specifications, including lysis with a digestion buffer and Proteinase $\mathrm{K}$ followed by magnetic bead separation of genomic DNA from cellular debris, proteins and RNA.

\section{Cytochrome c oxidase I amplifications and sequencing}

A multiplex mixture of II primers (Tab. 2; see Elbrecht and Leese 2017) with varying degrees of degeneracy were used to amplify the genomic DNA using a Hi-Plex approach (Nguyen-Dumont et al. 2013). The resulting amplicons 
TABLE I. Comprehensive list of species identified by BLAST search with sample sizes and mean counts of MVC ITS sequences indicating pathogen load. Families are listed alphabetically within order, and species are ordered from highest raw ITS count to lowest within family.

\begin{tabular}{|c|c|c|c|c|c|}
\hline & Species & $n$ & Family & Common name & Mean ITS \\
\hline \multirow[t]{21}{*}{ Hymenoptera } & Andrena vicina & 54 & Andrenidae & Neighborly Miner Bee & $7,423,087$ \\
\hline & Andrena carolina & 9 & Andrenidae & Blueberry bee & I40,52I.5 \\
\hline & Andrena clarkella & $\mathrm{I}$ & Andrenidae & Blueberry bee & 51,706 \\
\hline & Apis mellifera & 54 & Apidae & European Honey Bee & $2,136,683$ \\
\hline & Bombus bimaculatus & 16 & Apidae & Two-spotted Bumble Bee & $\mathrm{I}, 947, \mathrm{I} 50$ \\
\hline & Bombus impatiens & 56 & Apidae & Common Eastern Bumble Bee & I,777,II9 \\
\hline & Apis florea & I & Apidae & Dwarf Honey Bee & 262,579 \\
\hline & Bombus hypnorum & I & Apidae & Tree Bumblebee & IOI,649 \\
\hline & Bombus perplexus & 2 & Apidae & Confusing Bumblebee & 31,908 \\
\hline & Xylocopa virginica & $\mathrm{I}$ & Apidae & Eastern Carpenter Bee & 0 \\
\hline & Augochlorella sp. & $\mathrm{I}$ & Halictidae & Sweat Bee & 0 \\
\hline & Tryphon seminiger & I & Ichneumonidae & Parasitoid Wasp & 0 \\
\hline & Pristiphora cincta & I & Tenthredinidae & Saw Fly & 70,457 \\
\hline & Empria maculata & I & Tenthredinidae & Saw Fly & 0 \\
\hline & Dolichovespula maculata & 6 & Vespidae & Bald-faced Hornet & $\mathrm{I0,018,580}$ \\
\hline & Vespula vidua & $\mathrm{I} 4$ & Vespidae & Widow Yellowjacket & 631,404 \\
\hline & Euodynerus foraminatus & I & Vespidae & Potter Wasp & 302,476 \\
\hline & Dolichovespula adulterina & I & Vespidae & Parasitic Wasp & 258,704 \\
\hline & Dolichovespula arenaria & 2 & Vespidae & Arial Yellowjacket & 102,962 \\
\hline & Vespula sp. & 4 & Vespidae & Widow Yellowjacket & 16,735 \\
\hline & Polistes fuscatus & I & Vespidae & Northern Paper Wasp & 0 \\
\hline \multirow[t]{23}{*}{ Diptera } & Delia antiqua & I & Anthomyiidae & Onion Fly & 0 \\
\hline & Pollenia labialis & $\mathrm{I}$ & Calliphoridae & Cluster fly & 0 \\
\hline & Pollenia pediculate & I & Calliphoridae & Cluster fly & 0 \\
\hline & Pollenia rudis & 3 & Calliphoridae & Cluster fly & 0 \\
\hline & Conops rondanii & $\mathrm{I}$ & Conopidae & Fly (Bee Parasite) & $\mathrm{I}, \mathrm{I} 96,82 \mathrm{I}$ \\
\hline & Dolichopodidae sp. & 3 & Dolichopodidae & Long-legged $\mathrm{Fly}_{\mathrm{y}}$ & 45,433 \\
\hline & Desmometopa sordida & I & Milichiidae & Freeloader Fly & 36,934 \\
\hline & Anthomyiinae sp. & I & Muscidae & House Fly & 0 \\
\hline & Coenosia tigrine & I & Muscidae & House Fly & 0 \\
\hline & Chrysopilus sp. & 3 & Rhagionidae & Snipe Fly & 0 \\
\hline & Chrysopilus proximus & 4 & Rhagionidae & Snipe Fly & 0 \\
\hline & Blaesoxiphasp. & 2 & Sarcophagidae & Flesh Fly & 0 \\
\hline & Leptocera erythrocera & $\mathrm{I}$ & Sphaeroceridae & Lesser Dung Fly & 88,580 \\
\hline & Syrphinae sp. & $\mathrm{I}$ & Syrphidae & Hover Fly & $\mathrm{I}, 670,285$ \\
\hline & Mallota posticata & 6 & Syrphidae & Hover Fly & 549,321 \\
\hline & Eristalis dimidiata & I & Syrphidae & Hover Fly & 0 \\
\hline & Parhelophilus sp. & 2 & Syrphidae & Hover Fly & 0 \\
\hline & Platycheirus hyperboreus & $\mathrm{I}$ & Syrphidae & Hover Fly & 0 \\
\hline & Chrysops carbonarius & II & Tabanidae & Deer Fly & 0 \\
\hline & Chrysops dawsoni & $\mathrm{I}$ & Tabanidae & Deer Fly & 0 \\
\hline & Epalpus signifer & 6 & Tachinidae & Bristly Fly & $3 \mathrm{I} 6,52 \mathrm{I}$ \\
\hline & Klugia marginata & $\mathrm{I}$ & Tachinidae & Bristle Fly & $\mathrm{I} 22,649$ \\
\hline & Gonia ornata & I & Tachinidae & Bristle Fly & 0 \\
\hline \multirow[t]{2}{*}{ Coleoptera } & Bibioninae sp. & I & Cantharidae & Soldier Beetle & 83,505 \\
\hline & Pterolophia formosana & I & Cerambycidae & Longhorn Beetle & 0 \\
\hline
\end{tabular}


TABLE 2. Cytochrome c Oxidase I (COI) primer sets targeting the Folmer region for DNA metabarcoding of insects.

\begin{tabular}{llll}
\hline Primer Name $^{*}$ & Primer Sequence & Amplicon Size & Citation \\
\hline Uni-MinibarRI & GAAAATCATAATGAAGGCATGAGC & 127 & Meusnieretal 2008 \\
Uni-MinibarFI & TCCACTAATCACAARGATATTGGTAC & 127 & Meusnieretal 2008 \\
ZBJ-ArtFIc & AGATATTGGAACWTTATATTTTATTTTTGG & 157 & Zealeetal 2010 \\
ZBJ-ArtR2c & WACTAATCAATTWCCAAATCCTCC & 157 & Zealeetal 2010 \\
LepFI & ATTCAACCAATCATAAAGATATTGG & 127 & Hebertetal 2004 \\
EPT-long-univR & AARAAAATYATAAYAAAIGCGTGIAIIGT & 127 & Hajibabaeietal 20II \\
MLepFI-Rev & CGTGGAAAWGCTATATCWGGTG & 218 & Brandon-Mongetal 2015 \\
BFI & ACWGGWTGRACWGTNTAYCC & 217 & herein \\
BRI & ARYATDGTRATDGCHCCDGC & 217 & herein \\
L499 & ATTAATATACGATCAACAGGAAT & 178 & VanHoudtetal 2010 \\
H2123d & TAWACTTCWGGRTGWCCAAARAATCA & 178 & VanHoudtetal 2010 \\
\hline
\end{tabular}

"Primers described in doi: I0.3389/fenvs.2017.000I I (2017)

ranged in size from $\mathrm{I} 27$ to $2 \mathrm{I} 8 \mathrm{bp}$ and were sequenced on an Illumina HiSeq $X$ device running a 2xI50 paired-end configuration according to manufacturer directions (NovoGene, USA). The resulting raw sequences were processed using CLC Genomics Workbench version 9.5.3 (Qiagen, USA) to merge the paired reads and to conduct de novo assemblies using the default settings of CLC. The resulting contigs were BLAST searched (blastn, using nonredundant database) in CLC batch mode at the NCBI using default settings. Contigs receiving $\mathrm{IO}$ or more hits were examined further to assign putative genus and species.

Estimation of $M$. vaccinii-corymbosi using a sequencing approach

Primers amplifying a 93bp portion of the M. vacciniicorymbosi internal transcribed spacer (ITS) region (Forward primer: AAG GGC AGA ACC TCT CCA CCC TT; Reverse primer: AGG GTT AGG TCA TTG GCG GG) were tested on genomic DNA extracted from insects kept in axenic conditions that were entirely free of MVC and insects that had MVC spores applied to them by physically dusting insect bodies with conidia collected from blighted blueberry tissues. The primers amplified a properly sized amplicon from the dusted insects and there was no amplification for MVC-free insects. To determine the amount of fungal ITS carried on wild insects, a competition-assay was devised. The assay included the above primers and a mock-ITS target which had the central bases replaced with a $28 \mathrm{bp}$ string of ATCG(x7). The exact $M$. vaccinii-corymbosi amplicon sequence was:

AAGGGCAGAACCTCTCCACCCTTTGTGTATTA TTACTTTGTTGCTTTGGCGGGCCGCCTCCGGGC CTCGCGTGCCCGCCAATGACCTAACCCT

The mock-ITS sequence, added to each PCR amplification, was (replaced bases in bold):

AAGGGCAGAACCTCTCCACCCTTTGTGTATTA TTAATCGATCGATCGATCGATCGATCGATCGGCC TCGCGTGCCCGCCAATGACCTAACCCT
A dilution series for the mock-ITS was tested to estimate the amount of mock template suitable for use as an amplification control and to determine the relative amount of exact $M$. vaccinii-corymbosi sequences in the insect samples. Amplification products were prepared for sequencing on an Illumina HiSeq X device running a 2 x I50 paired-end configuration using the KAPA Hyper-Prep PCR-free kit according to the manufacturer directions (KAPA Biosystems, Wilmington, Massachusetts, USA) and quantified using the KAPA qPCR quantification kit (KAPA, USA). The resulting sequences were then mapped to the above exact and mock ITS sequences, requiring $99 \%$ similarity across $99 \%$ of the sequence, and the number of exact sequences was divided by the number of mock sequences to provide an estimate of total exact sequences within an insect sample. From these estimates we can compare relative amounts of ITS sequences between insect species.

\section{Cage Trials}

From May 29 through June 2, 2017, cage trials were conducted daily to determine the number of fungal conidia deposited per visit on blueberry floral stigmatic surfaces by honey and bumble bees. One nucleus colony of A. mellifera was purchased on April I3, 2017 (New England Apiaries, Westfield Massachusetts USA) and transported to Wilbraham, Massachusetts USA (42.136N, $-72.434 \mathrm{~W})$ to an outdoor, south-facing Langstroth hive attached to a I.22 $\mathrm{x}$ $1.22 \times 2.44 \mathrm{~m}$ fiberglass insect screen enclosure (Phifer Inc., Tuscaloosa, Alabama, USA). All exits from the hive except those leading to the screen enclosure were secured, ensuring that bees could not forage outside. Two B. impatiens research colonies (with queen but no drones) were obtained from Biobest USA, Inc. (Leamington, Ontario, Canada) on May I0, 2017 and placed within a separate screen enclosure (one hive at each end) identical to that for $A$. mellifera. Both $A$. mellifera and $B$. impatiens were fed ad libitum sucrose and water solution (I:I) from inverted jar feeders and BeePro FD200 Pollen Substitute (Mann Lake Ltd., Hackensack, Minnesota, USA) on an open platform within the enclosure. 
To provide a source of conidia in cage trials, blighted, conidia-producing stems were collected from Quonquont Farm in Whately, Massachusetts, USA $(42.444 \mathrm{~N}$, $-72.639 \mathrm{~W}$ ) on a weekly basis from May 9 to 30, 2017. Blights were left on stems, which were set in Floralife cutflower solution (I5.63 ml/1 concentration; Floralife North America, Waterboro, South Carolina USA) prior to use. To assess transfer of conidia to flowers, clippings with unopened floral clusters were taken from the same orchard on the same dates that blighted tissues were collected. These clippings were also provided Floralife solution and kept separate from blighted tissues in an enclosed area to prevent contamination from wild pollinator visitation. Only newly opened 'virgin' flowers were used in trials.

Artificial arrays of blighted tissue and virgin flowers were created by inserting blights and flowers into a $30 \mathrm{~cm} \times 15 \mathrm{~cm}$ x $5 \mathrm{~cm}$ foam block. Blocks were placed next to sucrose feeders so they could be easily located by foraging bees. Three clippings with blight (one blighted patch per clipping) and three clippings with virgin flowers (I-3 flowers per clipping) were used in each trial. To ensure there was no difference in blight sizes used in each trial, the length and width of blighted tissue on each blight was measured and were not significantly different between honeybee and bumblebee trials $\left(F_{1,36}=2.36\right.$, $P=0.1332$ ).

To begin each honeybee trial, the gate from the hive to the enclosure was closed, leaving only a small number of foraging bees in the enclosure. The array was observed until a honey bee visited blighted tissue, and bees were not allowed to contact a flower until after visiting blights. If bees were investigating a flower before contacting blight, they were pushed away manually. For blighted tissue, we define 'visit' as an insect fully landing on a blight with cessation of wing movement. The visit time was recorded from moment of landing and cessation of wing movement to departure. Once the visiting bee moved to a flower, we recorded the time spent within the corolla in contact with reproductive parts. The bee was removed from the enclosure after a single visit, and the clipping with visited flowers was removed and returned to a weatherproof screen enclosure in Floralife solution. Stigmas of visited flowers were harvested after three days and fixed in 90\% ethanol until subsequent fluorescence microscopy (as in Lehman et al. 2007) to determine how many fungal spores were deposited on the stigma. Clippings of both blighted tissue and floral tissue were discarded after the first visit. We ultimately collected 20 samples where honeybees foraged on blights and then flowers, in which we could measure conidial deposition.

Honeybees were far more apt to visit blighted tissues than bumblebees; $B$. impatiens had to be coaxed to forage on blighted tissue. Individual $B$. impatiens were chilled to $4^{\circ} \mathrm{C}$ for 20 minutes and then placed and allowed to waken on blighted tissues amongst a floral array similar to that used in honeybee trials; once bumblebees warmed they were more likely to forage. The time spent foraging on blights was measured starting from the first sustained, consistent movement of the bee abdomen lasting longer than one second on blights and ending when the bee left the tissue. Bumblebee visits to flowers were measured using the same honeybee protocols described above, and we collected 24 samples where bumblebees moved from blights to flower and we could measure conidial deposition.

To quantify conidia deposited on floral reproductive surfaces, stigmas were examined using fluorescence microscopy (Lehman et al. 2007). Stigmas were removed from $\mathrm{EtOH}$ solution and rinsed twice in sterile $\mathrm{dH}_{2} \mathrm{O}$. Stigmas were then cleared and fixed for 2 hours at $60^{\circ} \mathrm{C}$ in $0.3 \%$ trichloroacetic acid dissolved in a $3: \mathrm{I} \mathrm{vol} / \mathrm{vol}$ solution of $95 \% \mathrm{EtOH}$ and chloroform. Stigmas were again rinsed twice with sterile $\mathrm{dHOH}$ and softened in $8 \mathrm{M}$ sodium hydroxide for $20 \mathrm{~min}$ at $60^{\circ} \mathrm{C}$. Stigmas were then stained in $0.1 \%$ methyl blue in $0.1 \mathrm{M} \mathrm{K}_{3} \mathrm{PO}_{4}$ ( $\mathrm{pH} \mathrm{I}$ ) and again rinsed twice in $\mathrm{dH} 2 \mathrm{O}$. Styles were bisected longitudinally on a glass microscope slide and viewed using a Chroma 31000 filter set (Chroma Technology Corp., Bellows Falls, VT) excitation filter $(300-400 \mathrm{~nm}$, barrier filter $400 \mathrm{~nm}$, emitter filter 4I0$500 \mathrm{~nm})$.

\section{Statistical analysis}

For field-collected insects on blueberry, we analysed two components of the potential to transmit MVC. First, we analysed the likelihood of insect species carrying MVC using a Chi squared test of independence, with species as the predictor and presence or absence of ITS sequence counts as the response. Then to assess differences in potential to transmit for insects that were carrying MVC, we used generalized linear models with negative binomial distributions (to adjust for overdispersion) and log link functions (glm.nb in the MASS package) to compare the pathogen load, defined as the number of MVC ITS sequences found on insect bodies, between species or functional groups, only including insects in which we detected the presence of MVC ITS sequences. 'Functional groups' included flies, social bees, and solitary bees as categories. Number of copies of MVC (both raw counts and values adjusted by insect bodyweight (ITS count/fresh body weight in g)) were compared with species or functional groups as fixed effects in separate models; there were no other factors in the models. Species with fewer than six samples (Tab. 3) were dropped from this analysis. To compare means of ITS sequence counts, we used Tukey's post hoc comparison in the MultComp package for $\mathrm{R}$ ( $\mathrm{R}$ Development Core Team 2018).

For the cage trials, foraging time on blights and flowers was analysed using ANOVA with species as a fixed factor. To determine whether $A$. mellifera or $B$. impatiens differed in deposition of conidia per floral visit, a generalized linear model with a Poisson distribution was used with 'species' as a predictor and number of conidia deposited as a response. GLMs and associated multiple comparisons were analysed in $\mathrm{R}$ (version 3.5.I, R Foundation for Statistical Computing), and all other statistical analyses were carried out using JMP Pro I3.2.I (SAS Institute Inc., Cary, NC, 1989-2007).

\section{RESULTS}

We identified 47 species of insects spanning 2I families visiting Vaccinium corymbosum flowers, 25 of which carried MVC on or in their bodies (Tab. I). Of the 232 specimens 
TABLE 3. Sample sizes and percentages of taxa testing positive for MVC. Species are listed alphabetically. Only species with sample sizes of 5 or greater were included.

\begin{tabular}{lllll}
\hline & Percent with MVC & $\begin{array}{l}\text { Individuals with } \\
\text { MVC }\end{array}$ & $\begin{array}{l}\text { Individuals } \\
\text { without MVC }\end{array}$ & Sample Size \\
\hline Bees & & & 5 & 9 \\
Andrena carolina & 44.4 & 4 & 29 & 52 \\
$\begin{array}{l}\text { Andrena vicina } \\
\text { Apis melifera }\end{array}$ & 44.2 & 23 & 12 & 52 \\
Bombus bimaculatus & 76.9 & 40 & 9 & 15 \\
Bombus impatiens & 40 & 6 & 24 & 54 \\
Flies & 55.6 & 30 & & 10 \\
Chrysops carbonarius & 0 & & 10 & 6 \\
Epalpus signifer & 83.3 & 5 & 1 & 6 \\
Mallota posticata & 100 & 6 & 0 & 6 \\
Wasps & & & & 14 \\
Dolichovespula maculata & 83.3 & 5 & 5 & 1 \\
Vespula vidua & 64.3 & 9 & 5 & \\
\hline
\end{tabular}
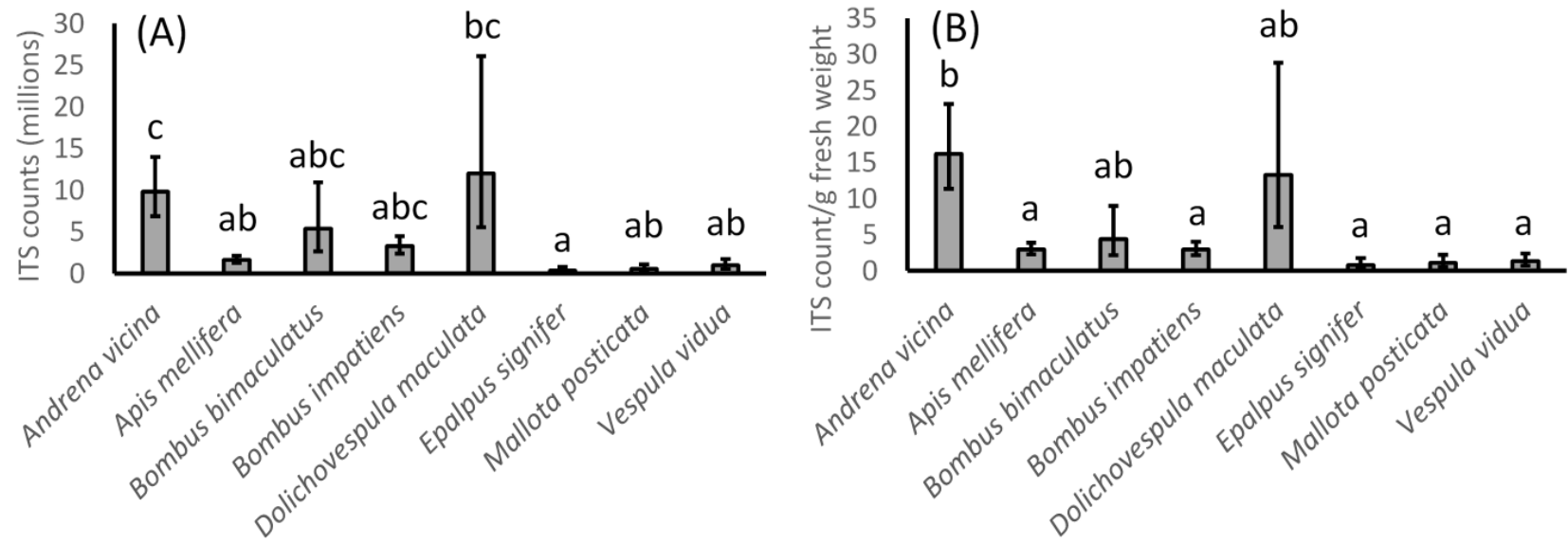

FIGURE I. Species comparison of MVC ITS regions for (A) counts in millions and (B) counts in millions adjusted by body size ( $\mathrm{g}$ fresh weight). Samples without MVC and species with fewer than five samples were not included in this analysis. Species with different letters are statistically different as determined by Tukey's post hoc comparisons. Means and error bars are back-transformed model estimates; error bars are exponentiated $+/$ - one standard error of the mean.

collected, I64 were comprised almost equally of B. impatiens, Andrena vicina and $A$. mellifera. We found that species was a significant predictor of the presence of $\operatorname{MVC}\left(\chi^{2}=37.157\right.$, $\mathrm{df}=9, P<0.000 \mathrm{I})$. Of all bee species, $A$. mellifera was most likely to carry MVC (76.9\% positive), while D. maculata (83.3\% positive) was highest among the wasps and Mallota posticata (I00\% positive) highest among the flies (Tab. 3). Of insects that carried MVC, comparison between generalized linear models with and without species as a fixed factor revealed that both raw counts of ITS sequences and those adjusted by insect body weight varied by species $\left(\chi^{2}=32.34\right.$, $\mathrm{df}=7, P<0.000 \mathrm{I}$ and $\chi^{2}=32.28$, df $=7, P<0.000 \mathrm{I}$, respectively). Additionally, results from Tukey's post hoc analyses show significant differences in both ITS and adjusted ITS means between species, with $A$. vicina carrying significantly more raw ITS sequences than $A$. mellifera, and more than both $A$. mellifera and B. impatiens when adjusted for body weight (Fig. I). Comparisons of generalized linear models with and without functional group as a fixed factor revealed that both raw counts of ITS sequences and those adjusted by body weight varied by functional group $\left(\chi^{2}=\right.$ 19.30, $\mathrm{df}=2, P<0.000 \mathrm{I}$ and $\chi^{2}=24.74 \mathrm{df}=2, P<$ 0.000I, respectively). Tukey's post hoc tests showed differences in ITS and adjusted ITS counts between functional groups (Fig. 2) with solitary species carrying the most pathogen load in both raw counts and analyses adjusted by bodyweight, and solitary species carrying more than flies in raw counts.

In our cage trials, $A$. mellifera and $B$. impatiens did not differ in conidia deposition $\left(\chi^{2}=0.01385, \mathrm{df}=\mathrm{I}, P=\right.$ 

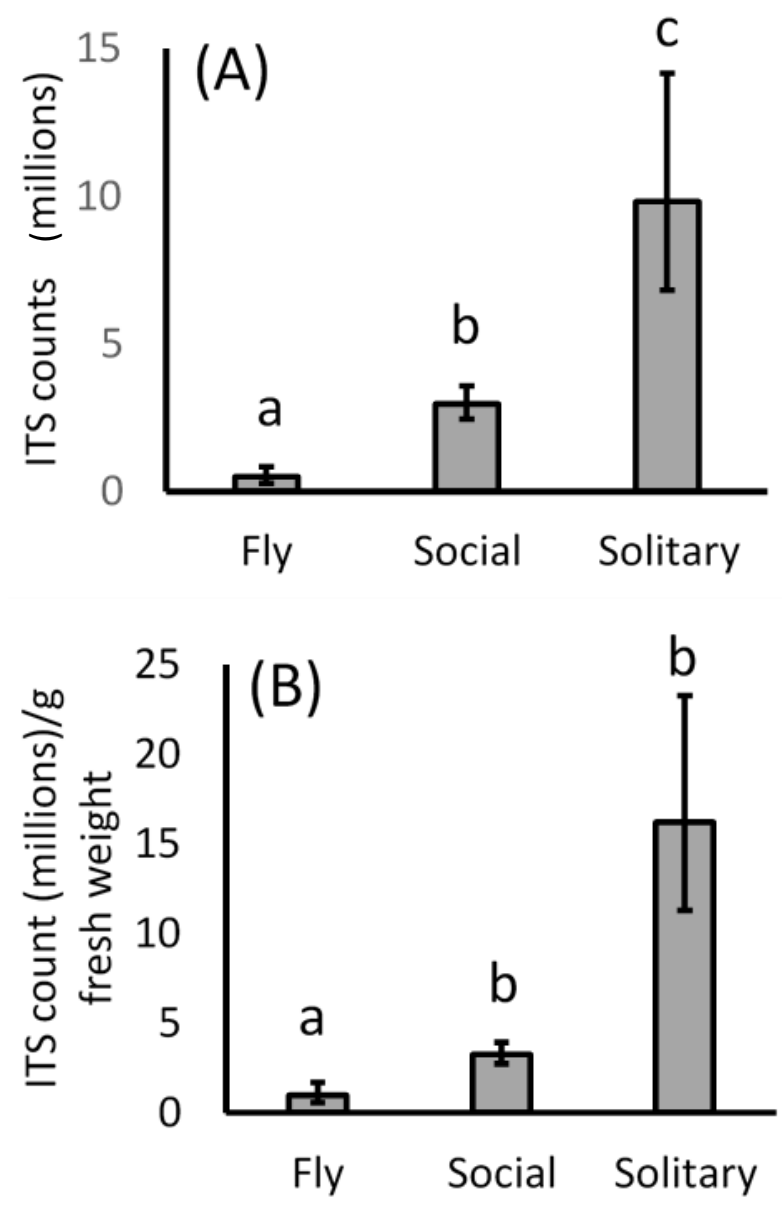

FIGURE 2. Functional group comparison of MVC ITS regions for (A) counts in millions and (B) counts in millions adjusted by body size ( $\mathrm{g}$ fresh weight); 'social' and 'solitary' refer to bee species. Groups with different letters are statistically different as determined by Tukey's post hoc comparisons. Means and error bars are backtransformed model estimates; error bars are exponentiated +/- one standard error of the mean.

0.9063; Fig. 3). A. mellifera and B. impatiens also did not differ in time spent foraging per flower $\left(F_{1,46}=0.1022, P=\right.$ 0.7507). Although A. mellifera spent $35.5 \%$ more time on blighted tissues than $B$. impatiens, this difference was not significant $\left(F_{1,51}=2.3577, P=0.1310\right)$.

\section{DISCUSSION}

Pollination is needed to maximize yield in highbush blueberry (Ehlenfeldt 200I), and a wide diversity of species visit V. corymbosum flowers (MacKenzie \& Eickwort I996; Tuell et al. 2009). Generally, bees are considered to be the primary pollinators (West \& McCutcheon 2009; Isaacs \& Kirk 2010). Our study found II bee species from three families visiting blueberry at a Massachusetts site, and other work investigating $V$. corymbosum in Oregon recorded 30 bee species spanning 5 families (Rao et al. 2009). Because bees are considered the most important pollinators, little attention has been paid to non-bee visitors. We also found non-bee hymenopteran visitors such as Ichneumonids and seven species of Vespids, including common and aerial yellowjackets and Bald-faced Hornets (Tab. I). The contribution of these species to blueberry pollination is unclear since these taxa may be nectar robbers, thieves, or searching for prey species instead of pollinating. We also identified I 3 species of flies (Tab. I); fly species are often overlooked as contributors to pollination services in both natural and agricultural systems (Larson et al. 200I; Ssymank et al. 2008). The decline of several bee species, including bumblebees and honeybees (Cameron et al. 20II; Smith et al. 2013) has prompted concerns over the effects on managed crop systems, including blueberry yield (Gibbs et al. 2016). Diverse assemblages of native pollinators may be able to provide 'biological insurance' that protects against the loss of key pollinator taxa (Winfree et al. 2007). Although not all of the insects found in our study are considered key pollinators, the broad community of insect visitors may indicate that $V$. corymbosum crops will be resilient to decline of particular pollinator species.

A wide variety of floral visitors were potential vectors of MVC. We found that 25 of the 46 floral visitor species tested positive for MVC (Tab. I), and of those species with six or more representatives, 9 out of $\mathrm{I} 0$ species tested positive (Tab. 3 ). The prevalence of MVC in our study is congruent with prior work that found 18 of 28 families and 5 of 6 orders that tested positive for the presence of MVC DNA (McArt et al. 2016). Overall, solitary bees carried more MVC than social bees, and social bees carried more than flies when comparing raw ITS counts (Fig. 2A). When comparing counts adjusted for body size, social and solitary bees did not differ significantly from one another but did carry more than flies (Fig. 2B). Below we address in turn specific patterns for bees, flies, and other insects.

Of bees in our study, A. mellifera tested positive for MVC most often, with over $76 \%$ of samples returning positive results, but the solitary bee Andrena vicina carried the most MVC when it was present. A. mellifera are widely used as supplemental pollinators due to their commercial availability, large colony size, and high pollination efficacy (Delaplane \& Mayer 2000). However, because MVC conidia mimic pollen grains in their mode of delivery (Ngugi \& Scherm 2004), A. mellifera may also be an efficient mummy berry vector. Thus, growers considering using honeybees as supplemental pollinators may want to consider their potential to also vector MVC. In our comparison of ITS regions adjusted for insect body size, we found that $A$. vicina had the highest average MVC ITS count when MVC was present. Andrena vicina is a solitary bee and common $V$. corymbosum forager and pollinator (Scott et al. 2016). In addition, one A. vicina sample had the highest MVC count of any insect sampled, with over 198 million ITS copies, almost three times as much as the next highest sample. In some cases, solitary bees can be more effective pollinators than A. mellifera (Vicens 2009). Additionally, many solitary bee species lack corbiculae, or pollen baskets, on their hind legs, instead carrying pollen on brushes of hairs (scopa) on their ventral abdomen or legs (Chambers 1946). While conidia mimic pollen grains in rough form and function, they are smaller than blueberry pollen and thus may be more easily transferred on scopa. This morphological difference may explain why MVC occurred in large quantities on $A$. vicina when it was present.

Congruent with prior work (McArt et al. 2016), we found that flies are less likely to carry MVC than bees, and when 
they do they carry MVC, they carry less. That said, we also found a great disparity in the presence of MVC between fly species (Tab. 3). For example, none of the ten specimens of Chrysops carbonarius (deer fly) tested positive for MVC. However, in Mallota posticata, a bee mimicking fly, all 6 samples tested positive for MVC. Behavioural differences are unlikely to explain this disparity in MVC presence since $M$. posticata and C. carbonarius are both floral visitors (Maier \& Waldbauer 1979; Karolyi et al. 2014), but morphological differences may play a role. Bee mimics have an abundance of body hairs compared to deer flies like Chrysops and other Tabanids, perhaps making the transfer of conidia more likely. On a broader scale, the wide variety of behaviours exhibited by Dipteran taxa found in our study may help to explain the variation in amounts of MVC. For example, Sarcophagidae species often feed on nectar (Rathman et al. 1990) and may be attracted to blights due to pseudoflower mimicry of floral volatiles, leaving shortly after discovering no nectar rewards. However, flies in the Sphaeroceridae are often larval microbial grazers on decaying plant material or fungi, and thus may visit blights at less frequent intervals and with different behaviours than other Dipteran taxa. Recent camera trap work has shown that flies were more likely to visit blighted blueberry tissues than bees, although bees were more likely to carry MVC than flies (McArt et al. 2016). This suggests that both blightvisiting behaviour and morphological features may work in tandem to maximize vectoring potential. Given the vast diversity of Dipteran species, more study relating fly behaviour to MVC transmission is needed.

Surprisingly, some of the highest MVC loads were carried by insects other than bees and flies. In our comparison of raw counts of MVC ITS regions on insects testing positive, $D$. maculata, or the Bald-faced hornet, carried the highest average MVC load of all insects sampled (Fig. I, Tab. I). Prior work using PCR to determine MVC presence on or in insect bodies found that the presence of MVC in Vespids was relatively low when compared to other taxa (McArt et al. 2016), which contrasts with our results in which 5 of 6 samples tested positive for MVC (Tab. 3). This suggests that while incidence of Vespids carrying MVC may vary, when MVC is present it may be carried in large quantities. Although D. maculata is primarily a predator upon insects including other Vespids, it often also acts as pollinator while searching for nectar (Jacobs 2015), and is commonly found foraging on $V$. corymbosum flowers (McArt et al. 2016). However, field observations during 2014 and 2016 suggest that large Vespid species may visit $V$. corymbosum flowers too infrequently to be a major vector of MVC, having comprised only $7 \%$ of all visitor observations (Boyer, unpublished data).

In cage trials we found that $A$. mellifera and $B$. impatiens did not differ in their ability to transfer conidia to blueberry stigmas after visiting blighted tissue, although we note that overall deposition was low (Fig. 3). Although A. mellifera spent $35.5 \%$ more time on blighted tissues than B. impatiens, this difference was not significant. Differences in vectoring success between $A$. mellifera and B. impatiens may be complex, and while single visit deposition is a good first step to understanding pathogen transmission efficacies between these taxa, it may not reflect deposition in the field due to differences in bee behaviour. Bees of either species may visit

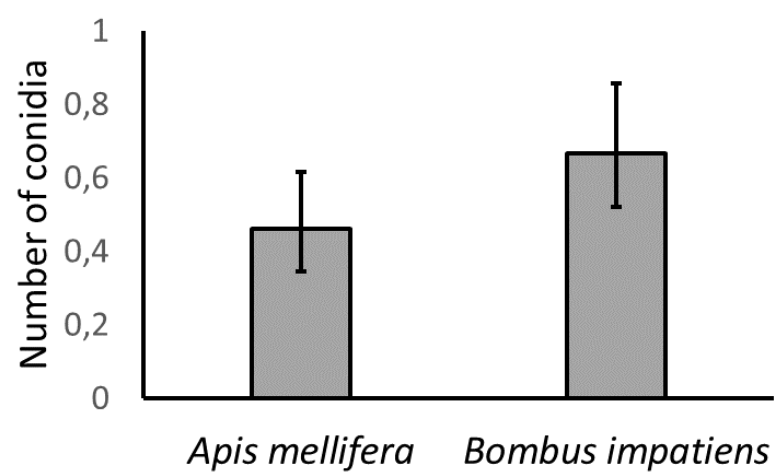

Figure 3. Mean conidia on stigmas visited by $A$. mellifera and B. impatiens in field cage trials. Bee species do not significantly differ in conidia deposited per single visit (see Results). Means and error bars are back-transformed model estimates; error bars are exponentiated $+/$ - one standard error of the mean.

multiple blights before any given flower, or vice versa, and the preference of $A$. mellifera to forage on blights may explain why A. mellifera was most likely to carry MVC in our field samples. Conidia deposition may rely on the cumulative effect of multiple visits, in which case single visits may not be enough to determine differences between species. Higher proportions of $A$. mellifera visitation are associated with greater incidence of fruit infection in field observations (Boyer, unpublished data). Thus, while our single-visit experiment demonstrated that conidial deposition per visit does not differ between these species, more comprehensive behavioural observations of visits to blights and flowers in the field may be necessary to understand transmission dynamics.

Encouraging native pollinators may help to decrease reliance on managed bees (Rogers et al. 20I4), but managed colonies of $A$. mellifera and $B$. impatiens are often used by growers (Delaplane \& Mayer 2000). Apis mellifera was more likely to carry MVC than $B$. impatiens and had a nonsignificant tendency to forage for longer on blighted tissue than B. impatiens. However, we found no significant difference in raw or adjusted ITS counts (Fig. I), nor in number of conidia deposited by $A$. mellifera and B. impatiens (Fig. 3). In addition to considering potential to vector MVC, pollination efficiency is of course a key characteristic when deciding whether and which species to use for supplemental pollination. Bombus impatiens are more effective extracting blueberry pollen due to their sonication behaviour, as blueberries have poricidal anthers adapted to buzz-pollinators (Delaplane \& Mayer 2000). A. mellifera often have difficulty legitimately pollinating blueberry flowers due to corolla structure, orientation, and a lack of buzz-pollination behaviour (Delaplane \& Mayer 2000). Despite the lack of sonication behaviour, honeybees may incidentally release small amounts of pollen while retrieving nectar from blueberry flowers (Javorek et al. 2002). Although the amount pollen released is small compared to buzz-pollination on a per-visit basis, differences in colony size between the two species may increase overall honeybee pollination effectiveness. Bumblebee colonies have hundreds of individuals, while a single honeybee colony often has tens of thousands. A recent study investigating efficacy of highbush blueberry pollinators found that while per-visit efficiency of $A$. mellifera was low, they 
were also the most abundant pollinators observed in the field (Rogers et al. 2013), but this was often dependent on the presence of managed hives. While we speculate that $A$. mellifera may be more likely to vector MVC than $B$. impatiens as well as being a less effective pollinator, further data are needed to make responsible recommendations for whether and which supplemental pollinators to use to maximize yield and minimize disease transmission.

Blueberry is an important economic crop in the United States whose pollinator community has been previously described (MacKenzie \& Eickwort 1996; Ross et al. 2017). Our study adds to this knowledge by providing molecular identification of the floral visitor community to the species level. Additionally, our study is the first to assess relative quantities of MVC carried on insect bodies, as well as to evaluate differences in pathogen transmission between two commonly supplemented pollinator species. All of the bee species and many of the fly species we collected tested positive for MVC, and of those that carry the pathogen, D. maculata carried the most in terms of raw counts, but $A$. vicina carried the most when adjusted for body size. Although honeybees were more likely to carry MVC than bumblebees we found no significant difference between the amount of MVC carried by bumblebees and honeybees, nor was there a significant difference in per visit deposition. In total, our findings increase our understanding of the potential for both wild and managed pollinator species to contribute to the vectoring of a highly damaging blueberry pathogen.

\section{ACKNOWLEDGEMENTS}

We thank Quonquont orchard for the use of their blueberry crop for insect, flower, and blight collection. Kurt Lamour of Floodlight Genomics for DNA extraction, quantification, and processing. H. Danielle Capps and the Scherm Lab at the University of Georgia for providing extracted Monilinia vaccinii-corymbosi DNA samples, and BioBest Sustainable Crop Management for the donation of two bumblebee colonies. We also thank J. Lehman for his guidance working with this system and in fluorescence microscopy protocols. We thank G. Snyder for his assistance with field insect collection. Thanks to Elizabeth Connor and Katherine Dorfman for the use of their fluorescence microscopy equipment. This work was made possible by funding from the United States Department of Agriculture National Institute of Food and Agriculture award 2016-6701I-24722, the Lotta M. Crabtree Fellowship, and the Organismic and Evolutionary Graduate Program at the University of Massachusetts Amherst.

\section{REFERENCES}

Adler LS, Irwin RE (2006) Comparison of pollen transfer dynamics by multiple floral visitors: Experiments with pollen and fluorescent dye. Annals of Botany 97:14I-I50.

Batra LR (1983) Monilinia vaccinii-corymbosi(Sclerotiniaceae) - Its biology on blueberry and comparison with related species. Mycologia 75:13I-I52.

Batra LR, Batra SWT (1985) Floral mimicry induced by mummyberry fungus exploits host's pollinators as vectors. Science 228:IOII-IOI3.

Cameron SA, Lozier JD, Strange JP, Koch JB, Cordes N, Solter LF, Griswold TL (20II) Patterns of widespread decline in North American bumble bees. Proceedings of the National Academy of Sciences 108:662 LP-667.
Chambers VH (1946) An examination of the pollen loads of Andrena: The species that visit fruit trees. Journal of Animal Ecology I5:9-2I. [online] URL: http://www.jstor.org/stable/ $\underline{1621}$

Delaplane KS, Mayer DF (2000) Crop pollination by bees. CABI Publishing. [online] URL: www.cabi-publishing.org

Dobson A, Crawley W (1994) Pathogens and the structure of plantcommunities. Trends in Ecology \& Evolution 9:393-398.

Ehlenfeldt MK (200I) Self- and cross-fertility in recently released highbush blueberry cultivars. Hortscience 36:133-I35.

Elbrecht V, Leese F (2017) Validation and development of COI metabarcoding primers for freshwater macroinvertebrate bioassessment. Frontiers in Environmental Science 5:I I.

Garibaldi LA, Steffan-Dewenter I, Winfree R, Aizen MA, Bommarco R, Cunningham SA, Kremen C, Carvalheiro LG, Harder LD, Afik O, Bartomeus I, Benjamin F, Boreux V, Cariveau D, Chacoff NP, Dudenhöffer JH, Freitas BM, Ghazoul J, Greenleaf S, Hipólito J, Holzschuh A, Howlett B, Isaacs R, Javorek SK Kennedy CM, Krewenka KM, Krishnan S, Mandelik Y, Mayfield MM, Motzke I, Munyuli T, Nault BA, Otieno M, Petersen J, Pisanty G, Potts SG, Rader R, Ricketts TH, Rundlöf M, Seymour CL, Schüepp C, Szentgyörgyi H, Taki H, Tscharntke T, Vergara $\mathrm{CH}$, Viana BF, Wanger TC, Westphal C, Williams N, Klein AM (2013) Wild pollinators enhance fruit set of crops regardless of honey bee abundance. Science 339:1608 LP-I6II.

Gibbs J, Elle E, Bobiwash K, Haapalainen T, Isaacs R (2016) Contrasting pollinators and pollination in native and non-native regions of highbush blueberry production. PLOS ONE I I:e0I58937. [online] URL: https://doi.org/I0.I37I/ journal.pone.0158937

Herrera CM (1987) Components of pollinator quality Comparative analysis of a diverse insect assemblage. Oikos 50:79_ 90.

Isaacs R, Kirk A (2010) Pollination services provided to small and large highbush blueberry fields by wild and managed bees. Journal of Applied Ecology 47:84I-849.

Jacobs S (2015) Baldfaced Hornet Fact Sheet. PennState College of Agriculture Extension [online] URL: https://ento.psu.edu/ extension/factsheets/baldfaced-hornet

Javorek SK, Mackenzie KE, Kloet SP Vander (2002) Comparative pollination effectiveness among bees (Hymenoptera: Apoidea) on lowbush blueberry (Ericaceae: Vaccinium angustifolium). Annals of the Entomological Society of America 95:345-35I. [online] URL: http://dx.doi.org/10.1603/0013-8746(2002)095[0345: CPEABH72.0.CO

Jennersten O (1988) Insect dispersal of fungal disease: Effects of Ustilago infection on pollinator attraction in Viscaria vulgaris. Oikos 51:163-170.

Karolyi F, Colville JF, Handschuh S, Metscher BD, Krenn HW (20I4) One proboscis, two tasks: Adaptations to blood-feeding and nectar-extracting in long-proboscid horse flies (Tabanidae, Philoliche). Arthropod Structure \& Development 43:403-4I3.

Klein AM, Vaissiere BE, Cane JH, Steffan-Dewenter I, Cunningham SA, Kremen C, Tscharntke T (2007) Importance of pollinators in changing landscapes for world crops. Proceedings of the Royal Society B-Biological Sciences 274:303-313.

Larson BMH, Kevan PG, Inouye DW (200I) Flies and flowers: taxonomic diversity of anthophiles and pollinators. The Canadian Entomologist 133:439-465.

Lehman JS, Igarashi S, Oudemans P V (2007) Host resistance to Monilinia vaccinit-corymbosi in flowers and fruits of highbush blueberry. Plant Disease 9I:852-856. 
MacKenzie KE, Eickwort GC (1996) Diversity and abundance of bees (Hymenoptera: Apoidea) foraging on highbush blueberry (Vaccinium corymbosum L.) in central New York. Journal of the Kansas Entomological Society 69:185-194. [online] URL: http://www.jstor.org/stable/25085716

Maier CT, Waldbauer GP (1979) Diurnal activity patterns of flower flies (Diptera: Syrphidae) in an Illinois sand area. Annals of the Entomological Society of America 72:237-45.

McArt SH, Koch H, Irwin RE, Adler LS (20I4) Arranging the bouquet of disease: floral traits and the transmission of plant and animal pathogens. Ecology Letters 17:624-36.

McArt SH, Miles TD, Rodriguez-Saona C, Schilder A, Adler LS, Grieshop MJ (2016) Floral scent mimicry and vector-pathogen associations in a pseudoflower-inducing plant pathogen system. Plos One II: e0I6576I.

Ngugi HK, Scherm H (2004) Pollen mimicry during infection of blueberry flowers by conidia of Monilinia vaccinii-corymbosi. Physiological and Molecular Plant Pathology 64:I 13-I23.

Ngugi HK, Scherm H, Lehman JS (2002) Relationships between blueberry flower age, pollination, and conidial infection by Monilinia vaccinii-corymbosi. Phytopathology 92:1 104-I 109.

Nguyen-Dumont T, Pope BJ, Hammet F, Southey MC, Park DJ (2013) A high-plex PCR approach for massively parallel sequencing. BioTechniques 55:69-74.

Norelli JL, Jones AL, Aldwinckle HS (2003) Fire blight management in the twenty-first century: Using new technologies that enhance host resistance in apple. Plant Disease 87:756-765. [online] URL: https://doi.org/10.1094/PDIS.2003.87.7.756

Olsen KM (1997) Pollination effectiveness and pollinator importance in a population of Heterotheca subaxillaris (Asteraceae). Oecologia I09:I I4-I2I.

Primack RB, Silander JA (1975) Measuring relative importance of different pollinators to plants. Nature 255:I43-I44.

R Development Core Team (2018) R: A language and environment for statistical computing.

Rao S, Stephen WP, White L (2009) Native bee pollinator diversity in Oregon blueberries. In: Acta Horticulturae. International Society for Horticultural Science (ISHS), Leuven, Belgium, pp 539-548. [online] URL: https://doi.org/10.I7660/ActaHortic. $\underline{2009.810 .71}$

Rathman ES, Lanza J, Wilson J (1990) Feeding preferences of flesh flies (Sarcophaga bullata) for sugar-only vs. sugar-amino acid nectars. The American Midland Naturalist I24:379-389. [online] URL: http://www.jstor.org/stable/2426188

Rogers SR, Tarpy DR, Burrack HJ (2013) Multiple criteria for evaluating pollinator performance in highbush blueberry (Ericales: Ericaceae) agroecosystems. Environmental Entomology 42:120II209. [online] URL: http://dx.doi.org/I0.1603/ENI2303
Rogers SR, Tarpy DR, Burrack HJ (2014) Bee species diversity enhances productivity and stability in a perennial crop Blenau W (ed). PLoS ONE 9:e97307. [online] URL: http://www.ncbi.nlm.nih.gov/pmc/articles/PMC40I6306/

Ross J, Foster D, Hillard P, Pendarvis S, Ray T (2017) Agricultural Statistics 2017. [online] URL: https://www.nass.usda.gov/ Publications/Ag_Statistics/2017/Complete Ag Stats 2017.pdf

Roy BA (1994) The use and abuse of pollinators by fungi. Trends in Ecology \& Evolution 9:335-339. [online] URL: http://dx.doi.org/10.1016/0169-5347(94)90154-6

Scott Z, Ginsberg H, Alm SR (2016) Native bee diversity and pollen foraging specificity in cultivated highbush blueberry (Ericaceae: Vaccinium corymbosum) in Rhode Island. Environmental Entomology 45:1432-I438. [online] URL: http://pubs.er. usgs.gov/publication/70179455

Shykoff JA, Bucheli E (1995) Pollinator visitation patterns, floral rewards and the probability of transmission of Microbotryum violaceum, a veneral disease of plants. Journal of Ecology 83:189_ 198. [online] URL: http://www.jstor.org/stable/2261557

Smith KM, Loh EH, Rostal MK, Zambrana-Torrelio CM, Mendiola L, Daszak P (2013) Pathogens, pests, and economics: Drivers of honey bee colony declines and losses. EcoHealth I0:434-445. [online] URL: https://doi.org/10.1007/sI0393$\underline{013-0870-2}$

Ssymank A, Kearns CA, Pape T, Thompson FC (2008) Pollinating flies (Diptera): A major contribution to plant diversity and agricultural production. Biodiversity 9:86-89. [online] URL: https://doi.org/10.1080/I4888386.2008.9712892

Stretch AW, Ehlenfeldt MK, Brewster V, Vorsa N, Polashock J (200I) Resistance of diploid Vaccinium spp. to the fruit rot stage of mummy berry disease. Plant Disease 85:27-30.

Tuell JK, Ascher JS, Isaacs R (2009) Wild bees (Hymenoptera: Apoidea: Anthophila) of the Michigan highbush blueberry agroecosystem. Annals of the Entomological Society of America I02:275-287. [online] URL: http://dx.doi.org/I0.1603 $\angle 008.102 .0209$

Vicens N (2009) Pollinating efficacy of Osmia cornuta and Apis mellifera (Hymenoptera: Megachilidae, Apidae) on "Red Delicious" Apple. Environmental Entomology 29:235-40.

West TP, McCutcheon TW (2009) Evaluating Osmia cornifrons as pollinators of highbush blueberry. International Journal of Fruit Science 9:I15-I25. [online] URL: https://doi.org/ I0.1080/I5538360902991303

Wightwick A, Walters R, Allinson G, Reichman S, Menzies N (2010) Fungicides: Environmental risks of fungicides used in horticultural production systems Carisse $\mathrm{O}(\mathrm{ed})$. In-Tech.

Winfree R, Williams NM, Dushoff J, Kremen C (2007) Native bees provide insurance against ongoing honey bee losses. Ecology letters I0:1105-III3. 